\title{
Parameters influencing deposit estimation when using water sensitive papers
}

\author{
Emanuele Cerruto, Claudia Aglieco, Sabina Failla, Giuseppe Manetto \\ Department DiGeSA, Section of Mechanics and Mechanisation, University of Catania, Italy
}

\begin{abstract}
The aim of the study was to assess the possibility of using water sensitive papers (WSP) to estimate the amount of deposit on the target when varying the spray characteristics. To identify the main quantities influencing the deposit, some simplifying hypotheses were applied to simulate WSP behaviour: log-normal distribution of the diameters of the drops and circular stains randomly placed on the images. A very large number (4704) of images of WSPs were produced by means of simulation. The images were obtained by simulating drops of different arithmetic mean diameter $(40-300 \mu \mathrm{m})$, different coefficient of variation (0.1-1.5), and different percentage of covered surface $(2-100 \%$, not considering overlaps). These images were considered to be effective WSP images and then analysed using image processing software in order to measure the percentage of covered surface, the number of particles, and the area of each particle; the deposit was then calculated. These data were correlated with those used to produce the images, varying the spray characteristics. As far as the drop populations are concerned, a classification based on the volume median diameter only should be avoided, especially in case of high variability. This, in fact, results in classifying sprays with very low arithmetic mean diameter as extremely or ultra coarse. The WSP image analysis shows that the relation between simulated and computed percentage of covered surface is independent of the type of spray, whereas impact density and unitary deposit can be estimated from the computed percentage of covered surface only if the spray characteristics (arithmetic mean and coeffi-
\end{abstract}

Correspondence: Emanuele Cerruto, Department DiGeSA, Section of Mechanics and Mechanisation, University of Catania, via S. Sofia 100, 95123 Catania, Italy.

Tel. +39.095 .7147514 - Fax: +39.095 .7147600 .

E-mail: ecerruto@unict.it

Key words: pesticides, image analysis, drop pulverisation.

Contributions: the authors contributed equally.

Conflict of interests: the authors declare no potential conflict of interests.

Received for publication: 1 July 2013.

Accepted for publication: 31 August 2013.

(C) Copyright E. Cerruto et al., 2013

Licensee PAGEPress, Italy

Journal of Agricultural Engineering 2013; XLIV:e9

doi:10.4081/jae.2013.e9

This article is distributed under the terms of the Creative Commons Attribution Noncommercial License (by-nc 3.0) which permits any noncommercial use, distribution, and reproduction in any medium, provided the original author(s) and source are credited. cient of variation of the drop diameters) are known. These data can be estimated by analysing the particles on the WSP images. The results of a validation test show good agreement between simulated and computed deposits, testified by a high (0.93) coefficient of determination.

\section{Introduction}

Spray deposit and superficial coverage are among the main factors influencing the biological efficacy of applied pesticides, as well as the environmental hazards. The correct deposit ensures the lethal dose on the target, while for non-systemic products, coverage increases the probability of contact between pest and pesticide.

Both aspects are influenced by many other factors, among which the most important is the spray spectrum (Hewitt, 1997; Matthews, 2004; Nuyttens et al., 2007). The ideal spectrum will maximise spray efficiency for depositing and transferring the required dose to the target, while minimising off-target losses due to drift and run-off, and reducing operator exposure (Hewitt et al., 1998).

An efficient pesticide application should ensure uniform distribution of the droplets over the entire target, including the underside of the leaves. This can be better achieved with small droplets capable of drifting inside the canopy. In fact, since large droplets are heavier, they are not usually deflected by air movement, so their redistribution within the crop foliage is limited. Moreover, large droplets are more prone to roll off onto the ground, so increasing the environmental impact. Finally, large droplets are fewer in number, so reducing coverage and probability of reaching the pest target. On the other hand, if the droplets become too small, they are more subjected to drift and evaporation, and so do not reach the target.

Spray spectrum, therefore, plays a crucial role in reducing any negative impacts of pesticides on the environment and on public health. The European Directives 2009/127/CE and 2009/128/CE recognise the use of pesticides as posing threats both to human health and the environment and therefore a sustainable use of pesticides should be established, taking account of precautionary and preventive approaches. Moreover, the design, construction and maintenance of machinery for pesticide application play a significant role in reducing the adverse effects of pesticides on human health and the environment (European Commission, 2009a, 2009b).

Foliar deposit is currently assessed by adding suitable tracers to the mixture, then spraying and measuring the amount that reaches the target, while foliar coverage is assessed by analysing the impact of the drops on suitable artificial targets. Widely used tracers are water-soluble dye such as Poinceau Red, yellow tartrazine, fluorescent products (Pergher, 2004; Cerruto, 2007; Jamar et al., 2010) or metal chelates such as copper, manganese, and zinc (Cross et al., 2001; Ade and Pezzi, 2001; Solanelles et al., 2006).

The most common artificial targets used to study superficial coverage are water sensitive papers (Salyani and Fox, 1999; Pezzi and Rondelli, 2000; Fox et al., 2003) and polyvinyl chloride (PVC) targets 
covered with silicon oil (Juste et al., 1990; Cerruto, 2001). Water sensitive papers (WSPs) allow for a quick assessment of the superficial coverage, while PVC targets allow for a better study of the particles, as they can also be used with high volume rates. The particle size distributions in the two target types are strictly correlated (Cerruto et al., 2009).

In the present study, the behaviour of water sensitive papers was simulated in order to estimate, in addition to the superficial coverage, the spray characteristics and the amount of deposit on the target.

\section{Materials and methods}

\section{Sprays}

Sprays can be classified according to the drop size spectra as established by the British Crop Protection Council (BCPC) classification scheme (Doble et al., 1985; Southcombe et al., 1997) or the ASAE S572.1 classification scheme (ASABE, 2009). Drop size can be described by means of a suitable probability density function (PDF) of the number of the drops. So, given a spray consisting of $N_{T}$ drops and using $f_{0}(D)$ to indicate the PDF of the drop number, the quantity $N_{T} f_{0}(D) d D$ represents the number of drops whose diameter ranges from $D$ to $(D+d D)$. Several PDFs have been proposed in literature to characterise the drop distribution, including the normal, the log-normal, the Rosin-Rammler and the gamma distributions (Ade and Fabbri, 2000; Babinsky and Sojka, 2002).

Beside the PDF, several mean diameters can be calculated to characterise the distribution (statistical moments) according to the formula:

$$
D_{p q}^{p-q}=\frac{\int_{0}^{\infty} D^{p} f_{0}(D) d D}{\int_{0}^{\infty} D^{q} f_{0}(D) d D}
$$

with $p$ and $q$ as typically positive integers. The mean diameters most commonly used are (Schick, 2008):

$D_{10}$ : the arithmetic mean diameter (AMD);

$D_{20}$ : the surface mean diameter;

$D_{30}$ : the volume mean diameter;

$D_{32}$ : the Sauter mean diameter, defined as the diameter of a drop having the same volume-to-surface area ratio as the total volume of all the drops to the total surface area of all the drops.

Other diameters referring to the volume of liquid sprayed or the number of drops can also be provided:

- $D_{v p}$ : a value so that the fraction $p$ of the total volume of liquid sprayed consists of drops with diameters smaller or equal to this value. Commonly used fractions are $10 \%(\mathrm{P}=0.1), 50 \%(\mathrm{P}=0.5)$, and $90 \%$ $(\mathrm{P}=0.9)$. The $D_{v 0.1}$ diameter is best suited to evaluate drift potential of individual drops, the $D_{v 0.5}$ [volume mean diameter (VMD)] diameter is mainly used to compare the average drop size from various atomisers, and the $D_{v 0.9}$ diameter is best suited when complete evaporation of the spray is required.

- $D_{n p}$ : a diameter so that the fraction $p$ of the total number of drops consists of drops with diameters smaller or equal to this value. Commonly used fractions are 10\% ( $\mathrm{P}=0.1), 50 \%(\mathrm{P}=0.5)$, and 90\% ( $\mathrm{P}=0.9)$. The $D_{n 0.5}$ diameter is also known as numeric mean diameter (NMD).

Parameters indicative of the uniformity of the drop size distribution are the relative span factor (RSF), defined as:

$$
R S F=\frac{D_{v 0.9}-D_{v 0.1}}{D_{v 0.5}}
$$

and the VMD-to-NMD ratio.

\section{The experiments}

Sprays with different AMD and different coefficient of variations (CV) were simulated. Reference AMD values $\left(D_{m}^{*}\right)$ ranged from 40 up to $300 \mu \mathrm{m}$ with $20 \mu \mathrm{m}$ intervals (14 values), while reference $\mathrm{CV}$ values $\left(C V^{*}\right)$ ranged from 0.1 to 1.5 with 0.2 intervals (8 values). Drop diameters $(D)$ were log-normal distributed according to the PDF function:

$$
f_{0}(D)=\frac{1}{\sqrt{2 \pi} \sigma D} e^{-\frac{(\ln D-\mu)^{2}}{2 \sigma^{2}}}
$$

Expected mean $E$, variance Var and coefficient of variation $C V$ are:

$$
E=e^{\mu+\frac{1}{2} \sigma^{2}} ; \quad \operatorname{Var}=\left(e^{\sigma^{2}}-1\right) e^{2 \mu+\sigma^{2}} ; \quad C V=\sqrt{e^{\sigma^{2}}-1}
$$

Fixing $E=D_{m}^{*}$ and $C V=C V^{*}$, Equations (4) allow the calculation of $\mu$ and $\sigma$ :

$$
\mu=\frac{1}{2} \ln \frac{D_{m}^{*}}{1+C V^{* 2}} ; \sigma=\sqrt{\ln \left(1+C V^{* 2}\right)}
$$

Images of WSPs $2 \times 7 \mathrm{~cm}$ in size were produced, with reference values of superficial coverage $S^{*}$ (not considering overlaps) ranging from $2 \%$ up to $10 \%$ with $2 \%$ intervals and from $10 \%$ up to $100 \%$ with $10 \%$ intervals (14 values). For each reference value of mean diameter, superficial coverage and $\mathrm{CV}$, three replicates were carried out, so producing a total of 4704 images.

Simulation was developed according to the following procedure: i) given the reference values of mean diameter $D_{m}^{*}(\mu \mathrm{m})$ and coefficient of variation $C V^{*}$, calculate $\mu$ and $\sigma$ according to the Equation (5) and then produce the drop diameter population $(D)$ according to the Equation (3). The number of drops was calculated on the basis of the reference value of superficial coverage $S^{*}(\%)$. Due to the intrinsic variability of the simulation process, when the error between simulated and reference values was greater than $1 \%$, other drop populations were produced;

ii) given the drop diameters $D(\mu \mathrm{m})$, produce the corresponding stain diameters $D_{s}(\mu \mathrm{m})$. Stain diameters were estimated using the equation:

$$
D_{s}=0.938 \cdot D^{1.143}
$$

devised by the Authors by analysing the spread factor i.e. the ratio between stain diameter and drop diameter (QInstruments) (Figure 1); iii) produce the WSP images by randomly allocating the stains, considered to be circular shaped. Images were produced with a resolution of $1200 \mathrm{dpi}$, sufficient to detect particles $24 \mu \mathrm{m}$ in diameter;

iv) compute and store all the data used to produce each image: drop diameter population $(D)$, simulated values of percentage of covered 
surface $S_{S}$ (not considering overlaps), arithmetic mean $\left(D_{m S}\right)$, coefficient of variation $\left(C V_{S}\right)$ and volume median diameter $\left(V M D_{S}\right)$ of the drops, impact density $I D_{S}$ (number of drop/ $/ \mathrm{cm}^{2}$ ), and unitary deposit $d_{S}$ $\left(\mu \mathrm{L} / \mathrm{cm}^{2}\right)$.

All the procedures were implemented using the open source software $R$ (R Development Core Team, 2012).

\section{Data analysis}

The images produced via simulation were analysed using ImageJ software (Abramoff et al., 2004) as real WSP images. The software detects the particles, without distinguishing between the overlapped ones, and provides some summary data for each image (percentage of covered surface $S_{C}$, particle density $P D_{C}$ i.e. number of particles $/ \mathrm{cm}^{2}$ ), as well as some data for each particle (area and shape descriptors). These data were correlated with the ones used to produce the images, and in particular the trends of $S_{S}, I D_{S}$ and $d_{S}$ versus $S_{C}$ were studied varying the spray characteristics $\left(D_{m}^{*}\right.$ and $\left.C V^{*}\right)$.

Subsequently, studying the area of each particle detected by ImageJ, other quantities were computed, among which: i) the equivalent diameter $D_{s c}$ of each particle (that of the circle with the same area); ii) the diameter $D_{C}$ of the drop capable of producing a stain with diameter $D_{s}$; the calculation was carried out by inverting Equation (6); iii) the coefficient of variation $C V_{C}$ and the arithmetic mean diameter $D_{m C}$ of these drops; iv) the unitary deposit $d_{C}\left(\mu \mathrm{L} / \mathrm{cm}^{2}\right)$ due to these drops.

Again, these data were correlated with the theoretical data used to produce the images, and in particular the trends of $d_{S}$ versus $d_{C}, C V_{C} v e r$ sus $S_{C}$ and $D_{m C}$ versus $S_{C}$ varying the spray characteristics and image features were analysed. All statistical analyses and graphical representations were carried out using the same $R$ software.

\section{Results and discussion}

\section{Drop populations}

Simulated sprays were classified according to the ASAE S572.1 standard (ASABE, 2009), considering, as classification criterion, only the VMD. The number of images produced for each class is reported in Table 1. Due to the variability introduced by the coefficient of variation (Figure 2), sprays even with low AMD were classified as extremely or ultra coarse. This implies that the VMD alone is not adequate for spray description, especially in case of high values of CV, RSF or VMD-toNMD ratio. This last parameter grows very rapidly (up to 40) when the $\mathrm{CV}$ increases, especially in sprays with low AMD values. A more accurate classification should be carried out by considering the cumulative volumetric droplet size curves and taking into account other volume and number diameters.

The WSP images corresponding to the drop distributions of Figure 2 are reported in Figure 3. The reference percentage of covered surface is $50 \%$ for all the images.

\section{Simulated and computed superficial coverage}

When the simulated (not considering overlaps) percentage of covered surface $S_{S}$ increases from $2 \%$ up to $100 \%$, the one $S_{C}$ computed from the images varies for each spray type (Figure 4). The regression equation of $S_{S}$ on $S_{C}$ is:

$$
S_{S}=a+b \ln \left(100-S_{C}\right)
$$

The coefficients $a$ and $b$ are reported in Table 2 . All the determina- tion coefficients (range 0.995-1.000) are highly significant.

Considering that the regression coefficients $a$ and $b$ are almost equal for all the spray types (the biggest differences are due to the ultra coarse spray only), it is possible to conclude that the relation between $S_{S}$ and $S_{C}$ is independent of the type of spray. Including all the values in the same model, the regression equation becomes:

$$
S_{S}=471.0-102.3 \ln \left(100-S_{C}\right)
$$

with coefficient of determination $\mathrm{R}^{2}$ equal to 0.997 highly significant. When the computed percentage of covered surface increases towards $100 \%$, the simulated one tends to move asymptotically towards positive

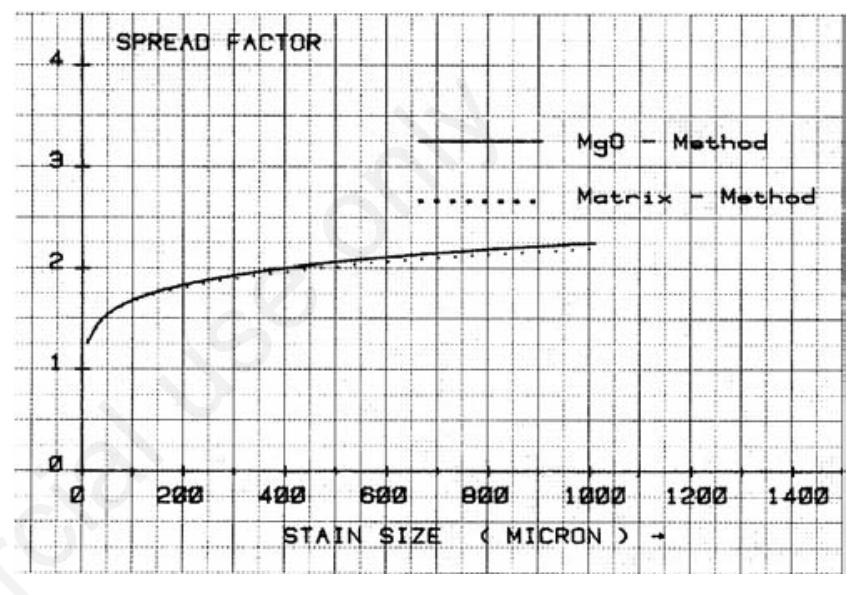

Figure 1. Spread factor versus spot diameter (QInstruments).
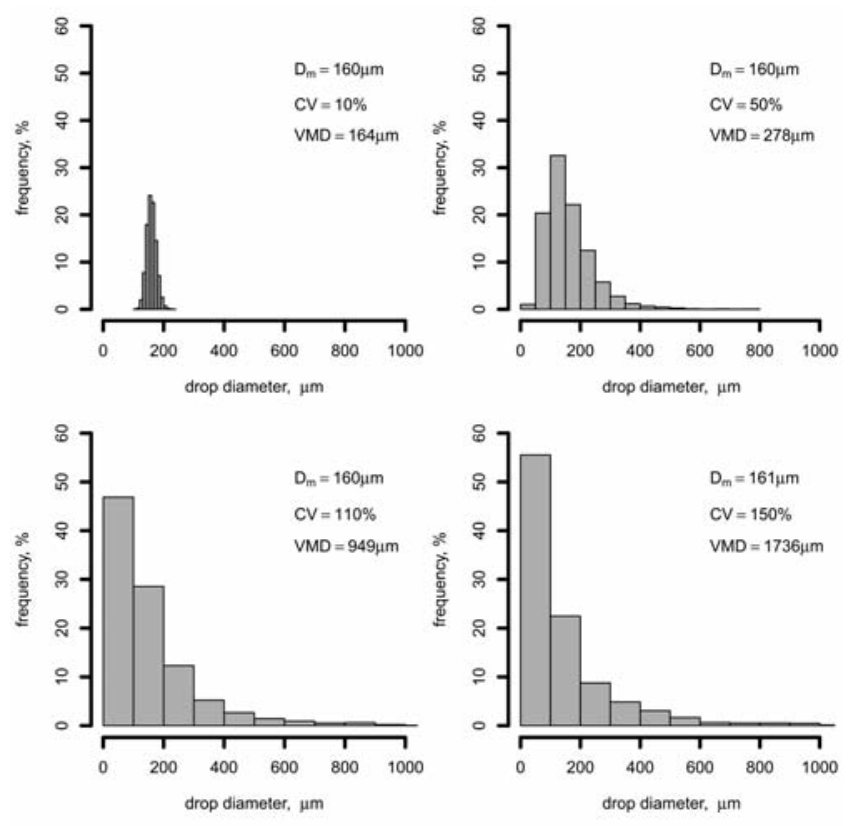

Figure 2. Examples of spray distributions. $D_{m}$, arithmetic mean diameter; $\mathrm{CV}$, coefficient of variation; VMD, volume median diameter. 
Table 1. Number of images simulated for each spray type.

\begin{tabular}{|c|c|c|c|c|c|c|c|c|}
\hline $\begin{array}{l}\text { Reference } \\
\text { diameter } \\
\text { ( } \mu \mathrm{m})\end{array}$ & $\begin{array}{c}X F \\
<50\end{array}$ & $\begin{array}{c}\text { Spray } \\
\text { VF } \\
50-136\end{array}$ & $\begin{array}{l}\text { cording to } \\
\mathrm{F} \\
136-177\end{array}$ & $\begin{array}{c}\text { ASAE S57 } \\
\text { M } \\
177-218\end{array}$ & $\begin{array}{c}\text { standard* } \\
\text { C }\end{array}$ & $\begin{array}{c}\mathrm{D}, \underset{\mathrm{mm}}{\mathrm{VC}}(\mathrm{A} \\
349-428\end{array}$ & $\begin{array}{c}\text { BE, 2009) } \\
X C \\
428-622\end{array}$ & $\begin{array}{c}\mathrm{UC} \\
>622\end{array}$ \\
\hline 40 & 84 & 84 & 29 & 13 & 43 & 12 & 36 & 35 \\
\hline 60 & 0 & 126 & 42 & 0 & 44 & 25 & 36 & 63 \\
\hline 80 & 0 & 85 & 41 & 29 & 42 & 13 & 45 & 81 \\
\hline 100 & 0 & 84 & 40 & 2 & 42 & 16 & 43 & 109 \\
\hline 120 & 0 & 42 & 42 & 41 & 41 & 4 & 44 & 122 \\
\hline 140 & 0 & 0 & 84 & 0 & 44 & 40 & 38 & 130 \\
\hline 160 & 0 & 0 & 42 & 42 & 42 & 19 & 33 & 158 \\
\hline 180 & 0 & 0 & 0 & 43 & 83 & 3 & 44 & 163 \\
\hline 200 & 0 & 0 & 0 & 42 & 69 & 15 & 44 & 166 \\
\hline 220 & 0 & 0 & 0 & 0 & 84 & 42 & 42 & 168 \\
\hline 240 & 0 & 0 & 0 & 0 & 84 & 40 & 17 & 195 \\
\hline 260 & 0 & 0 & 0 & 0 & 85 & 2 & 45 & 204 \\
\hline 280 & 0 & 0 & 0 & 0 & 78 & 6 & 49 & 203 \\
\hline 300 & 0 & 0 & 0 & 0 & 43 & 41 & 43 & 209 \\
\hline Total & 84 & 421 & 320 & 212 & 824 & 278 & 559 & 2006 \\
\hline
\end{tabular}

VMD, volume median diameter; $\mathrm{XF}$, extremely fine; $\mathrm{VF}$, very fine; F, fine; M, medium; C, coarse; VC, very coarse; XC, extremely coarse; UC, ultra coarse.

Table 2. Regression parameters of $S_{S}$ on $S_{C}$.

\begin{tabular}{lccccccc}
$\begin{array}{l}\text { Spray } \\
\text { type }\end{array}$ & LL & $\begin{array}{c}a \\
\text { E }\end{array}$ & UL & LL & b & UL & $\mathbf{R}^{2}$ \\
XF & 457.5 & 461.8 & 466.0 & -101.3 & -100.3 & -99.3 & 1.0000 \\
VF & 460.5 & 462.4 & 464.3 & -100.9 & -100.4 & -100.0 & 1.0000 \\
\hline F & 461.1 & 463.3 & 465.5 & -101.1 & -100.6 & -100.1 & 1.0000 \\
M & 461.6 & 464.3 & 466.9 & -101.5 & -100.8 & -100.2 & 0.9999 \\
\hline C & 464.0 & 465.4 & 466.8 & -101.4 & -101.1 & -100.7 & 0.9999 \\
VC & 463.9 & 466.3 & 468.7 & -101.8 & -101.3 & -100.7 & 0.9998 \\
\hline XC & 466.3 & 468.0 & 469.7 & -102.0 & -101.6 & -101.2 & 0.9997 \\
UC & 478.7 & 479.6 & 480.5 & -104.3 & -104.1 & -103.9 & 0.9949 \\
\hline
\end{tabular}

$a, b$, coefficients; LL, lower limit; E, estimated; UL, upper limit; XF, extremely fine; $\mathrm{VF}$, very fine; F, fine; M, medium; C, coarse; VC, very coarse; XC, extremely coarse; UC, ultra coarse.

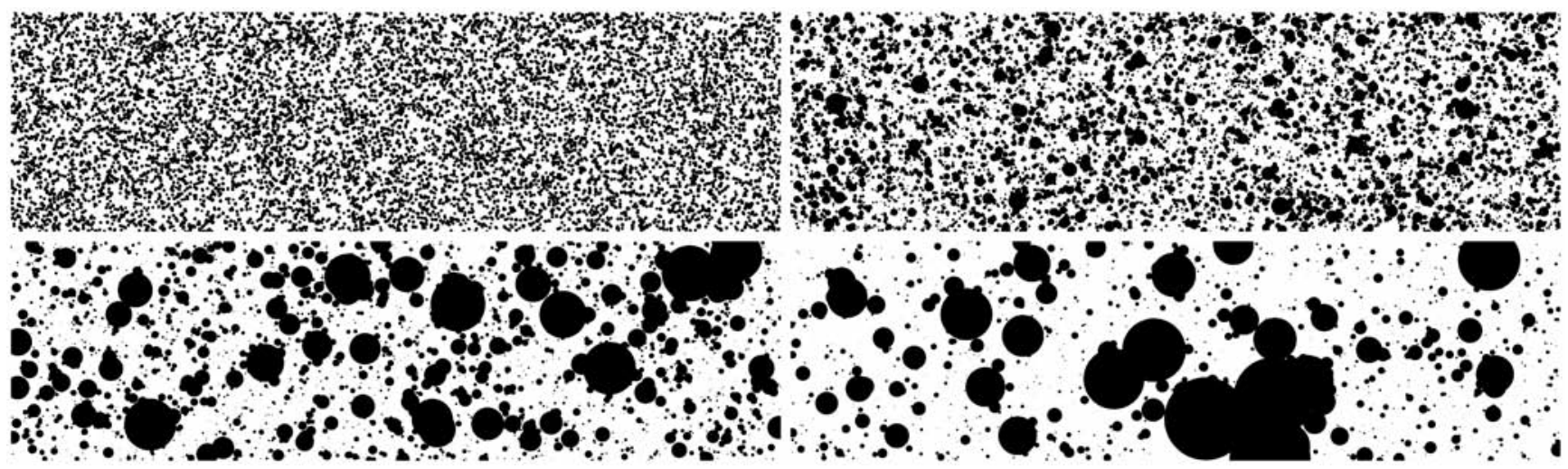

Figure 3. Water sensitive paper images corresponding to the drop distributions shown in Figure 2 . The reference coverage is $50 \%$ for all the images. 
infinity. According to Equation (8), when the simulated percentage of covered surface ranges from $10 \%$ up to $100 \%$, the computed percentage ranges from $9.4 \%$ up to $62.4 \%$ and then the overlap ranges from $0.6 \%$ up to $37.6 \%$.

\section{Unitary deposit}

Figure 5 reports the simulated unitary deposits $d_{s}\left(\mu \mathrm{L} / \mathrm{cm}^{2}\right)$ in function of the computed percentage of covered surface $S_{C}(\%)$ for some AMD values. The trends are well described by quadratic relations of the form:

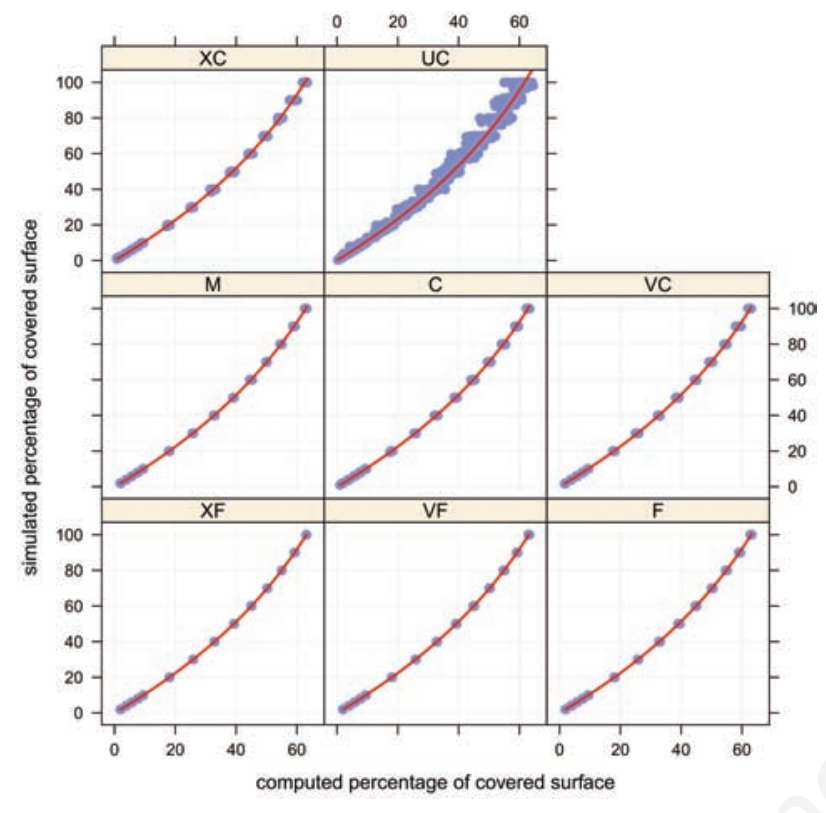

Figure 4. Correlations between simulated and computed percentage of covered surface at varying spray type. XF, extremely fine; $\mathrm{VF}$, very fine; $F$, fine; $M$, medium; $C$, coarse; VC, very coarse; $X C$, extremely coarse; UC, ultra coarse.

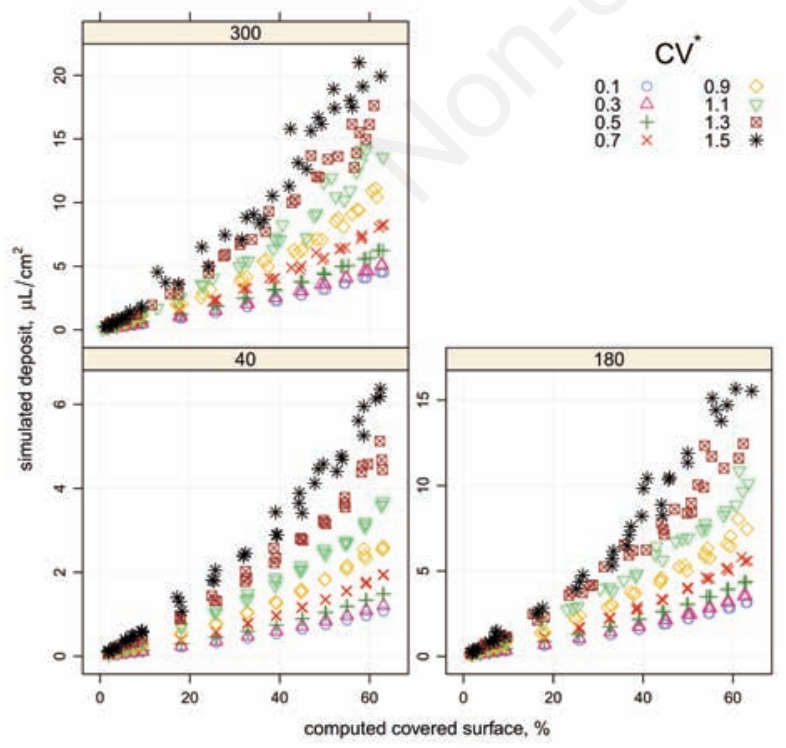

Figure 5. Examples of correlation between computed percentage of covered surface and simulated unitary deposit at varying mean and coefficient of variation $(\mathrm{CV})$ of the drop diameters.

$$
d_{S}=b_{0}+b_{1} S_{C}+b_{2} S_{C}^{2}
$$

with coefficients $b_{0}, b_{1}$ and $b_{2}\left(\mu \mathrm{L} / \mathrm{cm}^{2}\right)$ affected by mean and $\mathrm{CV}$ of the drop diameters (Figure 6). The coefficients of determination range from 0.933 up to 1.000 , and are highly significant. This implies that the deposit can be estimated from the superficial coverage, but only if the spray characteristics are known. The estimation of arithmetic mean and $\mathrm{CV}$ of the drop diameters requires an analysis of the particles.

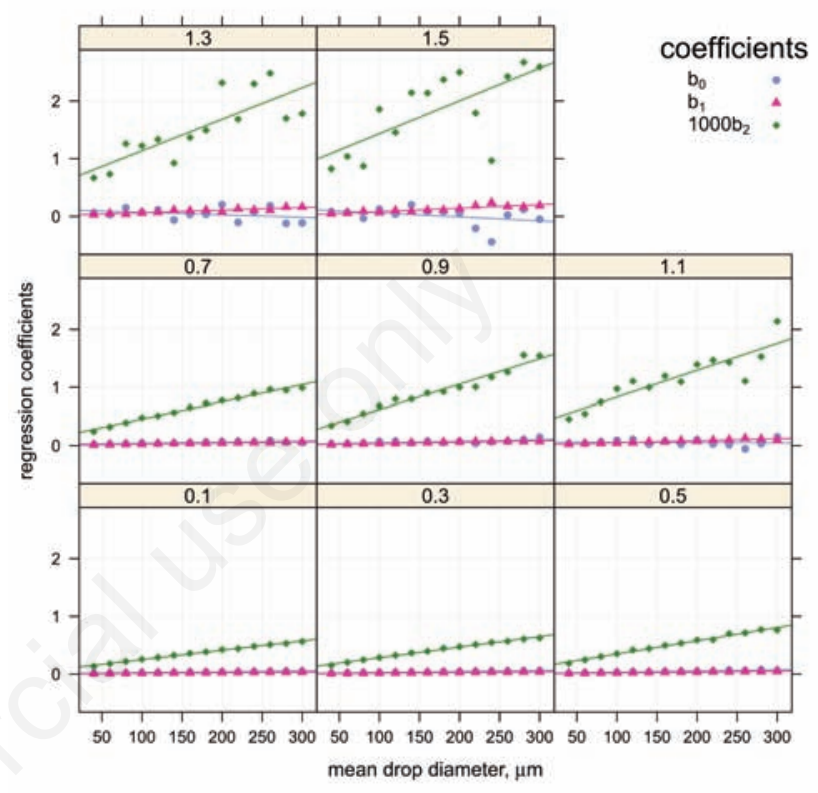

Figure 6. Coefficients $b_{0}, b_{1}$ and $b_{2}\left(\mu \mathrm{L} / \mathrm{cm}^{2}\right)$ at varying mean and coefficient of variation of the drop diameters for the calculation of the deposit according to the Equation 9.

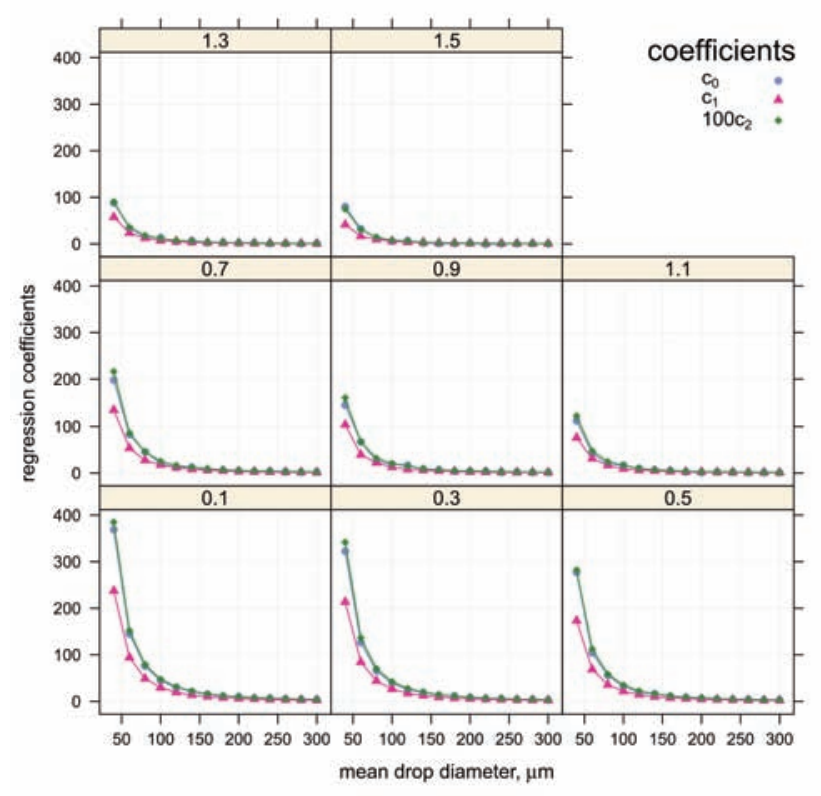

Figure 7. Coefficients $c_{0}, c_{1}$ and $c_{2}\left(\mathrm{~cm}^{-2}\right)$ at varying mean and coefficient of variation of the drop diameters for the calculation of the impact density according to the Equation 10. 


\section{Impact density}

The impact density $I D_{S}\left(\mathrm{~cm}^{-2}\right)$ (no. drops $\left./ \mathrm{cm}^{2}\right)$ increases in a quadratic manner versus the computed percentage of covered surface $S_{C}$ (\%):

$$
I D_{S}=c_{0}+c_{1} S_{C}+c_{2} S_{C}^{2}
$$

Again, the regression equation coefficients $c_{0}, c_{1}$ and $c_{2}\left(\mathrm{~cm}^{-2}\right)$ depend on mean and CV of the drop diameters (Figure 7). The coefficients of determinations range from 0.987 up to 1.000 .

\section{Particle analysis}

The analysis of the particles detected by ImageJ on the WSP images allows for the calculation of several quantities, among which spray characteristics, particle density and unitary deposit.

The first step was aimed at estimating the spray characteristics CV and AMD. To this end, the trends of $D_{m C}$ and $C V_{C}$ versus $S_{C}$, computed according to the procedure described in methodology, were analysed. As an example, Figure 8 reports the results from varying $\mathrm{CV}$ when $D_{m}^{*}$ $=140 \mu \mathrm{m}$ or from varying AMD when $C V^{*}=0.5$. Similar graphs were obtained for all the other test conditions.

An estimate of $\mathrm{CV}$ and AMD of the drop diameters can be obtained by extrapolating the trends of $D_{m C}$ and $C V_{C}$ to low $S_{C}$ values ( $\left.<5 \%\right)$. Figure 9 reports the relative errors, computed as:

$$
R E_{D_{m}}=\frac{D_{m}^{*}-D_{m C}}{D_{m}^{*}} ; \quad R E_{C V}=\frac{C V^{*}-C V_{C}}{C V^{*}}
$$

In most cases, these are less than 10\%: they are greater when estimating AMD less than $100 \mu \mathrm{m}$ or CV less than $20 \%$ or higher than $100 \%$.

The particle density versus $S_{C}$, in contrast to the impact density, due to the overlapping, reaches a maximum when the percentage of cov-

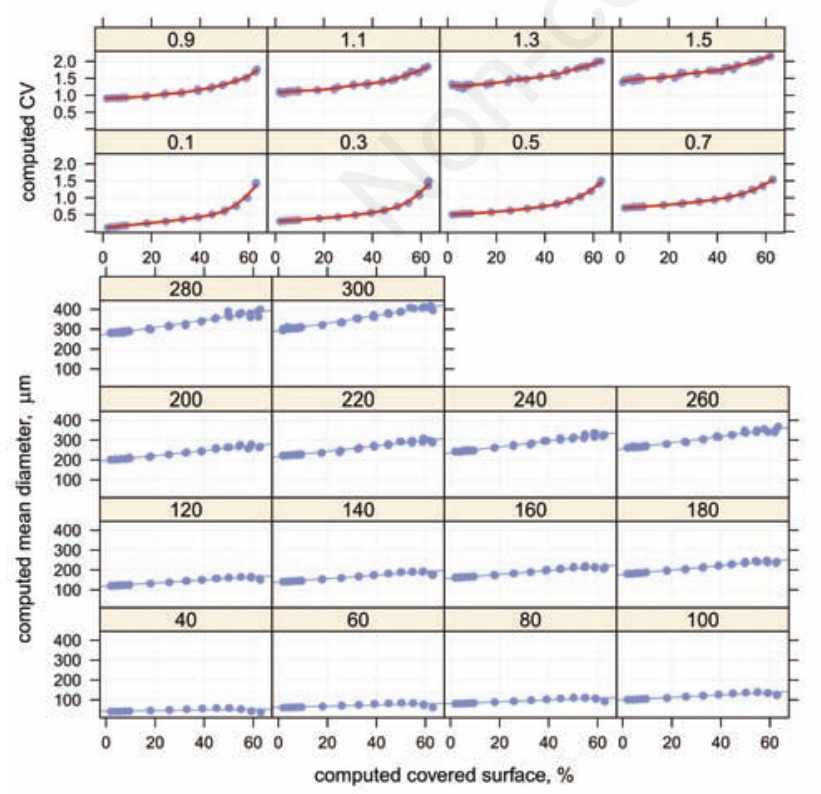

Figure 8. Examples of trends of computed coefficient of variation (CV) versus $S_{C}$ at fixed arithmetic mean diameter (AMD) (140 $\mu \mathrm{m})$ and of computed AMD versus $S_{C}$ at fixed CV (0.5). ered surface is approximately between $20 \%$ and $40 \%$ (Figure 10). Values can differ greatly, depending on the spray characteristics.

Finally, the particle analysis offers an alternative to Equation (9) to estimate the unitary deposit. As an example, the deposit $d_{C}\left(\mu \mathrm{L} / \mathrm{cm}^{2}\right)$, computed by analysing the particles, was related to that simulated $d_{s}$ $\left(\mu \mathrm{L} / \mathrm{cm}^{2}\right)$ when the $\mathrm{CV}$ was 0.5 (Figure 11). The interpolating functions take the form:

$$
d_{S}=a_{0}+a_{1} \cdot e^{-a_{2} \cdot d_{C}}
$$

where:

$a_{0}\left(\mu \mathrm{L} / \mathrm{cm}^{2}\right), a_{1}\left(\mu \mathrm{L} / \mathrm{cm}^{2}\right)$ and $a_{2}\left(\mathrm{~cm}^{2} / \mu \mathrm{L}\right)$ are coefficients depending on the spray characteristics. Figure 12 reports their trend versus the mean drop diameter when the $\mathrm{CV}$ is 0.5 . Similar graphs were obtained at different CV values.

Altogether, the particle analysis on WSP images allows the main quantities of a spray application to be estimated: spray characteristics and unitary deposit.
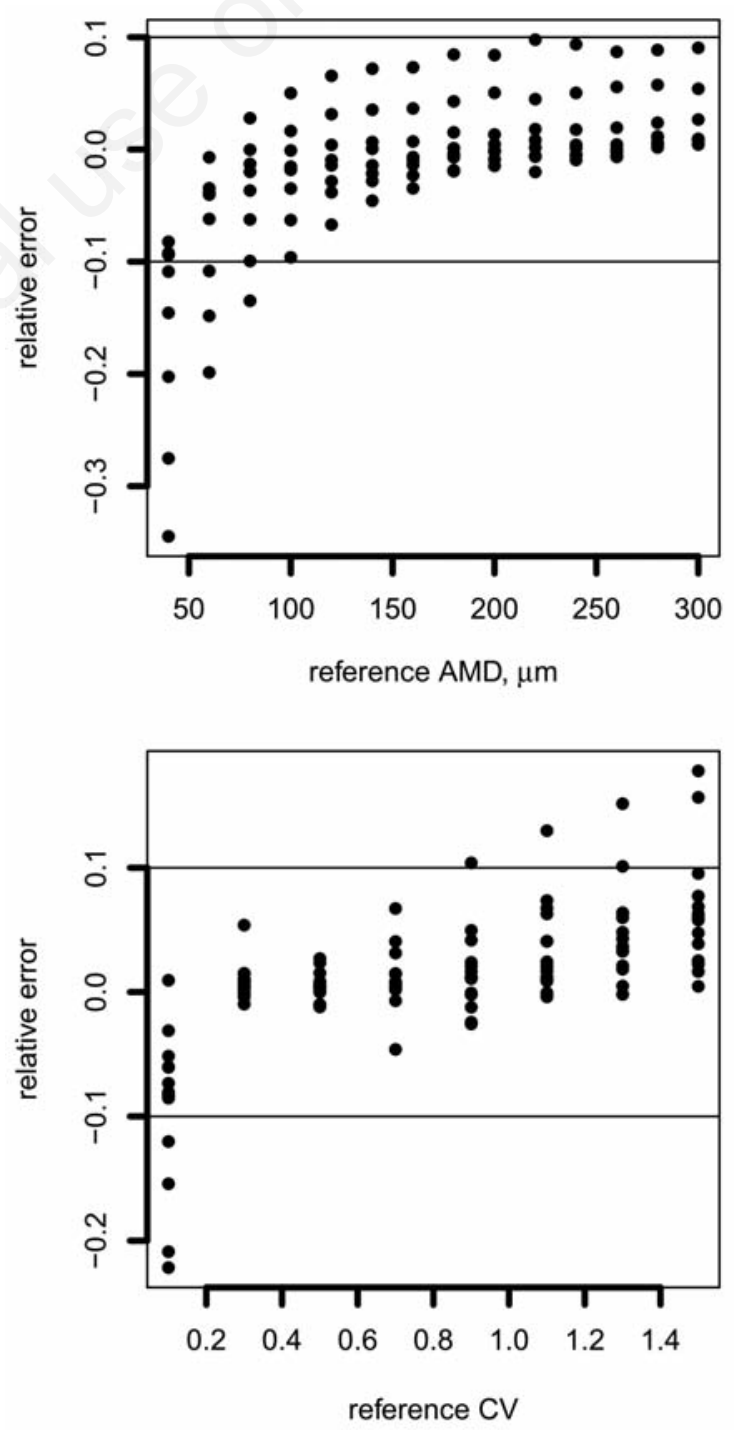

Figure 9. Relative error in estimating coefficient of variation (CV) and arithmetic mean diameter (AMD) of drop diameters. 


\section{Validation}

The previous procedure was validated by applying it to a spray characterised by $D_{m}^{*}=150 \mu \mathrm{m}$ and $C V^{*}=0.8$ (values not included in the experimental design). WSP images were simulated by considering impact densities increasing from 50 to $600 \mathrm{~cm}^{-2}$ with intervals of 50 . No control was applied to the effective drop population simulated, as in a real-life spray application: the effective $\mathrm{CV}$ ranged from 0.76 to 0.98 , the effective AMD ranged from 146 to $155 \mu \mathrm{m}$. Each test condition was

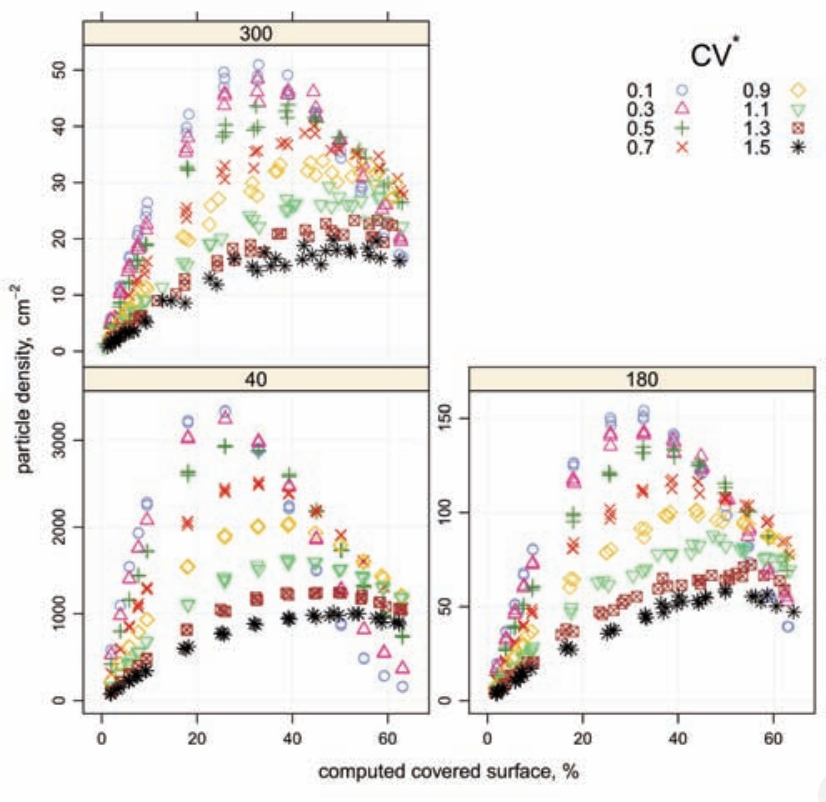

Figure 10. Example of correlation between particle density and computed percentage of covered surface at varying mean and coefficient of variation $(\mathrm{CV})$ of the drop diameters.

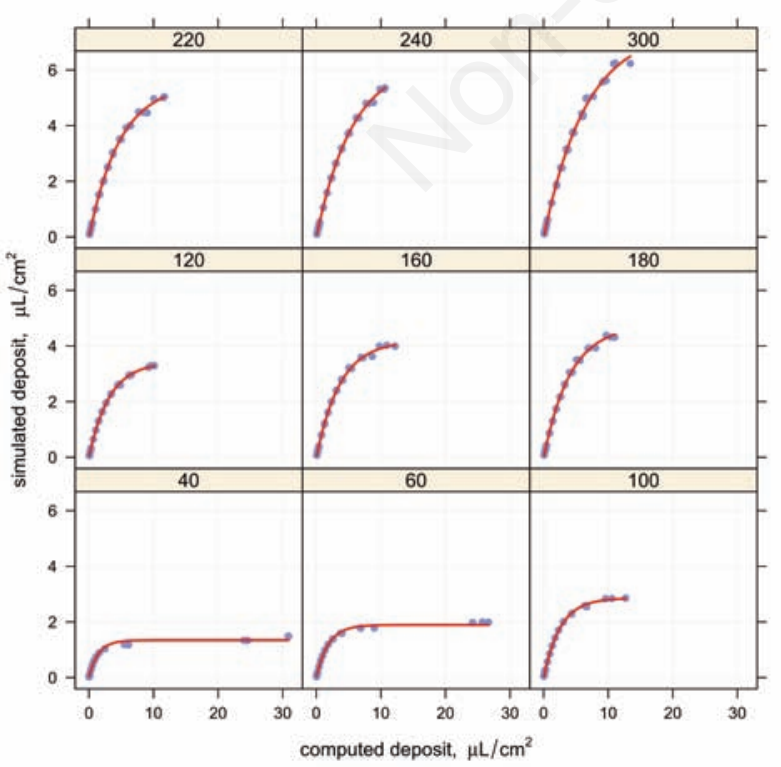

Figure 11. Simulated versus computed deposit for some arithmetic mean diameter values when $\mathrm{CV}=0.5$. replicated three times for a total of 36 images.

The trends of $D_{m C}$ (linear) and $C V_{C}$ (local regression) versus $S_{C}$ are reported in Figure 13; their extrapolation at $S_{C}=0$ provides an estimation of $150 \mu \mathrm{m}$ for the AMD and 0.82 for the CV. The relative error with respect to the reference quantities is approximately $2 \%$.

Estimation of the unitary deposit using Equation (9) requires the coefficients $b_{0}, b_{1}$ and $b_{2}$ to be known; these were computed on the basis of Figure 6, fixing $D_{m}=150 \mu \mathrm{m}, C V=0.82$ and by using linear interpolations. The computed values were:
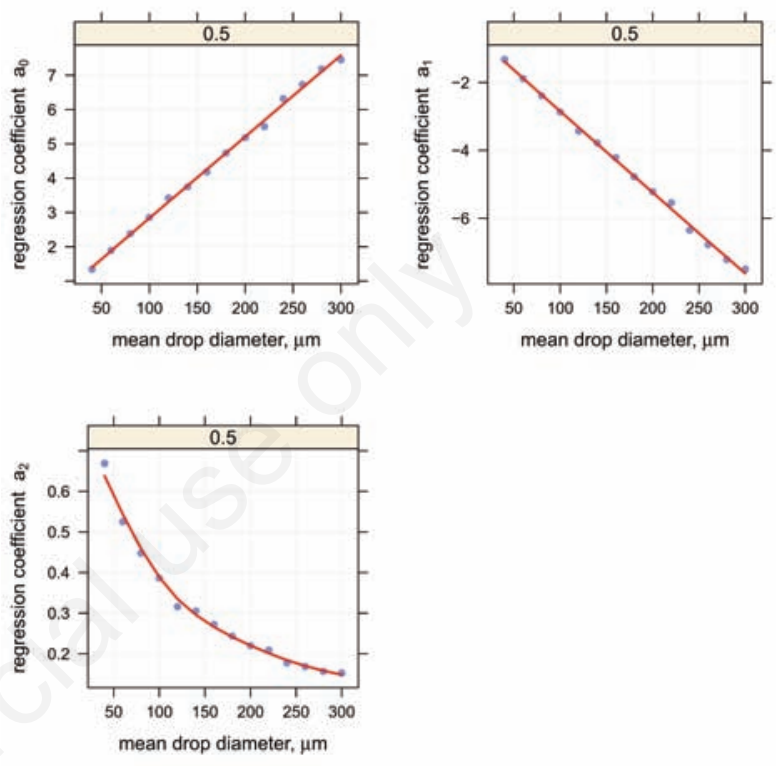

Figure 12. Coefficients $a_{0}\left(\mu \mathrm{L} / \mathrm{cm}^{2}\right), a_{1}\left(\mu \mathrm{L} / \mathrm{cm}^{2}\right)$ and $a_{2}\left(\mathrm{~cm}^{2} / \mu \mathrm{L}\right)$ at varying mean drop diameter when $\mathrm{CV}=0.5$ for the calculation of the unitary deposit according to Equation 12.
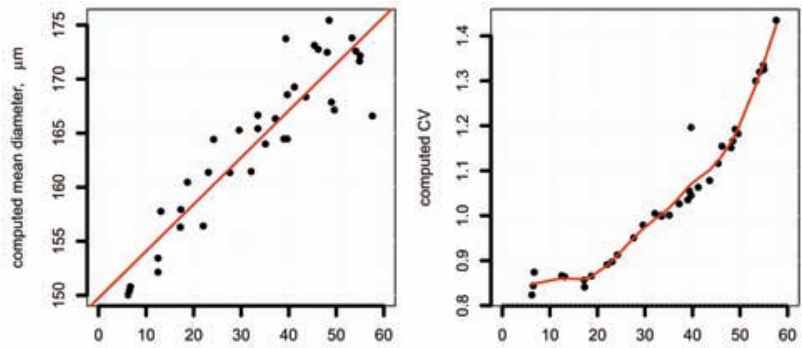

computed covered surface, \%

computed covered surface, \%
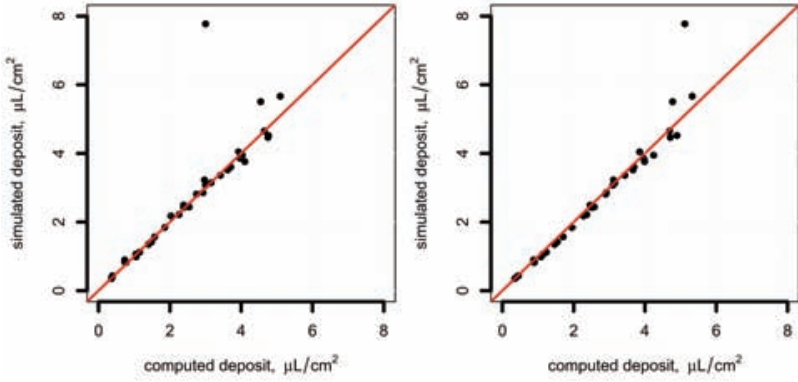

Figure 13. Results of the validation test: estimate of arithmetic mean diameter, coefficient of variation and unitary deposit using Equation 9 (left) and Equation 12 (right). 


$$
b_{0}=0.048 \mu \mathrm{L} / \mathrm{cm}^{2} ; \quad b_{1}=0.045 \mu \mathrm{L} / \mathrm{cm}^{2} ; \quad b_{2}=0.744 / 1000 \mu \mathrm{L} / \mathrm{cm}^{2}
$$

The comparison between computed and simulated deposit is reported in Figure 13. Only one deposit was heavily underestimated due to the presence of a very big drop on the image that masks other drops.

When using Equation 12, the coefficients $a_{0}, a_{1}$ and $a_{2}$, calculated on the basis of graphs (Figure 12) were:

$$
a_{0}=7.375 \mu \mathrm{L} / \mathrm{cm}^{2} ; a_{1}=-7.435 \mu \mathrm{L} / \mathrm{cm}^{2} ; a_{2}=0.163 \mathrm{~cm}^{2} / \mu \mathrm{L}
$$

The simulated deposits versus the computed ones are reported in Figure 13 and show a better agreement with respect to the previous approach, testified by a higher coefficient of determination $(0.926 \mathrm{vs}$ 0.786 ) and a lower residual sum of square (7.51 vs 23.50). The particle analysis is, therefore, more precise in estimating the unitary deposit, even if it requires a greater computational effort.

\section{Conclusions}

The results of this study show that, under the hypotheses of spherical drops, log-normal distribution of drop diameters and circular stains, the spray characteristics in terms of mean drop diameter, coefficient of variation, impact density and unitary deposit, besides the covered surface, can be assessed by using water sensitive papers.

This can be demonstrated by the following considerations.

- The relation between simulated superficial coverage and computed superficial coverage is highly significant and independent of the type of spray; this means it is easy to estimate the overlap between the particles.

- The relations between simulated unitary deposit and computed superficial coverage are highly significant, as are the relations between impact density and computed superficial coverage. However, these relations are affected by CV and AMD of the drop diameters.

- The particle analysis on the WSP images allows the spray characteristics CV and AMD and the unitary deposit to be estimated.

- The validation test shows a good agreement between simulated and computed values (AMD, CV, and unitary deposit).

It is also important to emphasise that, as far as the drop population is concerned, the classification criterion based on the VMD alone is not adequate to describe the spray because sprays with low arithmetic mean diameter, in the presence of high $\mathrm{CV}$, would be classified as extremely or ultra coarse.

Therefore, the analysis of the water sensitive paper images provides a complete description of the treatment in terms of unitary deposit, drop diameter, particle and impact density. Further studies are necessary to cover other situations (e.g. different probability distribution functions of drop diameter in order to evaluate whether the results are distribution independent) and to verify the models under experimental conditions. Moreover, the results will be useful in calibrating the sprayers according to the recently introduced regulations in order to further reduce the environmental impact of chemical pest control.

\section{Main symbol list}

\section{Drop distribution}

$D$ : drop diameter

$f_{0}(D)$ : probability density function of drop diameter

$D_{p q}$ : mean diameters (statistical moments of distribution $f_{0}$ )

$D_{v p}$ : diameters referring to the volume

$D_{n p}$ : diameters referring to the number

$\mu, \sigma$ parameters of the log-normal distribution

\section{Reference values}

$D_{m}^{*}$ : reference arithmetic mean diameter

$C V^{*}$ : reference coefficient of variation

$S^{*}$ : reference percentage of covered surface (not considering overlaps)

Simulated values (for each water sensitive paper image)

$D_{s}$ : stain diameter due to a drop of diameter $D$

$S_{S}$ : simulated percentage of covered surface (not considering overlaps)

$D_{m s}$ : simulated arithmetic median diameter

$C V_{s}$ : simulated coefficient of variation

$V M D_{S}$ : simulated volume mean diameter

$I D_{S}$ : simulated impact density

$d_{s}:$ simulated unitary deposit

Computed values (from each water sensitive paper image)

$S_{C}$ : computed percentage of covered surface (considering overlaps)

$D_{s c}$ : equivalent diameter of each particle

$D_{C}$ : diameter of a drop capable of producing a stain with diameter $D_{s C}$ $C V_{C}$ : computed coefficient of variation of the drops with diameter $D_{C}$ $d_{C}$ : computed unitary deposit

\section{Regression equations}

$a, b$ : coefficients in the regression equation of $S_{S}$ on $S_{C}$

$a_{0}, a_{1}, a_{2}$ and $b_{0}, b_{1}, b_{2}$ : coefficients in the regression equations of $d_{S}$ on $d_{C}$ $c_{0}, c_{1}, c_{2}$ : coefficients in the regression equation of $I D_{S}$ on $S_{C}$

$R E_{D_{m}}$ : relative error on the estimate of $D_{m}^{*}$

$R E_{C V}$ : relative error on the estimate of $C V^{*}$

\section{References}

Abramoff M.D., Magelhaes P.J., Ram S.J. 2004. Image processing with ImageJ. Biophot. Int. 11:36-42.

Ade G., Fabbri C. 2000. Indagine teorica sul legame tra grado di copertura, numerosità e distribuzione della popolazione delle impronte sulle cartine idrosensibili. Riv. Ing. Agr. 2:104-8.

Ade G., Pezzi F. 2001. Results of field tests on a recycling air-assisted tunnel sprayer in a peach orchard. J. Agr. Eng. Res. 80:147-52.

ASABE (American Society of Agricultural and Biological Engineers) Standards. 2009. ANSI/ASAE S572.1: MAR2009. Spray nozzle classification by droplet spectra. ASAE, St. Joseph, MI, USA. Available from: http://www.asabe.org/standards/images.aspx

Babinsky E., Sojka P.E. 2002. Modeling drop size distribution. Progr. Ener. Combustion Sci. 28:303-29.

Cerruto E. 2001. Caratterizzazione mediante analisi d'immagine di bersagli in PVC per prove di irrorazione. Riv. Ing. Agr. 2:101-7.

Cerruto E. 2007. Influence of airflow rate and forward speed on the spray deposit in vineyard, Riv. Ing. Agr. 1:7-14.

Cerruto E., Balloni S., Conti A., Caruso L. 2009. Caratteristiche di bersagli artificiali per lo studio delle gocce in prove di irrorazione. Proc. IX Natl. Congr. AIIA "Ricerca e innovazione nell'ingegneria 
dei biosistemi agro-territoriali", Ischia (NA), Italy, CD-ROM.

Cross J.V., Walklate P.J., Murray R.A., Richardson G.M. 2001. Spray deposits and losses in different sized apple trees from an axial fan orchard sprayer: 1. Effects of spray liquid flow rate. Crop Prot. 20:13-30.

Doble S.J., Matthews G.A., Rutherford I., Southcombe E.S.E. 1985. A system for classifying hydraulic and other atomizers into categories of spray quality. Proc. Br. Crop Prot. Conf. Weeds 3:1125-33.

European Commission. 2009a. Directive 2009/127/EC of the European Parliament and of the Council of 21 October 2009 amending Directive 2006/42/EC with regard to machinery for pesticide application. In: Official Journal, L 310/29, 25/11/2009, available from: http://eurlex.europa.eu/LexUriServ/LexUriServ.do?uri=0J:L:2009: 310:0029: 0033:en:PDF

European Commission. 2009b. Directive 2009/128/EC of the European Parliament and of the Council of 21 October 2009 establishing a framework for Community action to achieve the sustainable use of pesticides. In: Official Journal, L 309/71, 24/11/2009, available from: http://eur-lex.europa.eu/LexUriServ/LexUriServ.do?uri=0J:L:2009: 309:0071:0086:en:PDF

Fox R.D., Derksen R.C., Cooper J.A., Krause C.R., Ozkan H.E. 2003. Visual and image system measurement of spray deposits using water-sensitive paper. Appl. Eng. Agr. 19:549-52.

Hewitt A.J. 1997. The importance of droplet size in agricultural spraying. Atomization Spray 7:235-44.

Hewitt A.J., Valcore D.L., Teske M.E., Schick R.J. 1998. Droplet size classification for agricultural sprays. Proc. Ilass 11th Annual Conf. Liquid Atomization and Spray Systems, Sacramento, CA, USA, pp 55-59.

Jamar L., Mostade O., Huyghebaert B., Pigeon O., Lateur M. 2010. Comparative performance of recycling tunnel and conventional sprayers using standard and drift-mitigating nozzles in dwarf apple orchards. Crop Prot. 29:561-6.

Juste F., Sanchez S., Ibanez R., Val L., Garcia C. 1990. Measurement of spray deposition and efficiency of pesticide application in citrus orchard. J. Agr. Eng. Res. 46:187-96.

Matthews G.A. 2004. How was the pesticide applied? Crop Prot. 23:6513.

Nuyttens D., Baetens K., De Schampheleire M., Sonck B. 2007. Effect of nozzle type, size and pressure on spray droplet characteristics. Biosyst. Eng. 97:333-45.

Pergher G. 2004. Field evaluation of a calibration method for air-assisted sprayers involving the use of a vertical patternator. Crop Prot. 23:437-46.

Pezzi F., Rondelli V. 2000. The performance of an air-assisted sprayer operating in vines. J. Agr. Eng. Res. 76:331-40.

QInstruments. 2013. Water sensitive papers. Available from: http:// www.qinstruments.com/en/service/downloads/downloads-wsp.html Accessed: July 2013.

R Development Core Team. 2012. R: A language and environment for statistical computing. R Foundation for Statistical Computing, Vienna, Austria. Available from: http://www.R-project.org

Salyani M., Fox R.D. 1999. Evaluation of spray quality by oil- and water sensitive papers. Trans. ASABE 42:37-43.

Schick R.J. 2008. Spray technology reference guide: understanding drop size. Spraying Systems Co., Bulletin No. 459C. Available from: http://de.spray.com/Portals/0/pdf/B459c.pdf

Solanelles F., Escolà A., Planas S., Rosell J.R., Camp F., Gràcia F. 2006. An electronic control system for pesticide application proportional to the canopy width of tree crops. Biosyst. Eng. 95:473-81.

Southcombe E.S.E., Miller P.C.H., Ganzelmeier H., Van de Zande J.C., Miralles A., Hewitt A.J. 1997. The international (BCPC) spray classification system including a drift potential factor. Proc. Br. Crop Prot. Conf. Weeds 5A-I:371-80. 